\title{
First case of peritoneal cysticercosis in a non-human primate host (Macaca tonkeana) due to Taenia martis
}

\author{
Julie Brunet ${ }^{1,2^{*}}$, Bernard Pesson ${ }^{1}$, René Chermette ${ }^{3}$, Pierrick Regnard ${ }^{4}$, Felix Grimm5 ${ }^{5}$ Peter Deplazes ${ }^{5}$, Xavier Ferreira ${ }^{6}$, \\ Marcela Sabou ${ }^{1}$, Alexander W Pfaff ${ }^{1}$, Ahmed Abou-Bacar ${ }^{1}$ and Ermanno Candolfi ${ }^{1}$
}

\begin{abstract}
Background: Infections with larval stages (metacestodes) of a variety of taeniid species have been described in primates, including humans, with partial to severe clinical consequences. Taenia martis is a tapeworm of mustelids, and martens are mainly their definitive hosts in Central Europe. In the rodent intermediate host cysticerci develop in the pleural and peritoneal cavities. The present report describes a case of T. martis peritoneal cysticercosis in a Tonkean macaque.

Findings: An abdominal mass was detected in a 3-year-old male Tonkean macaque (Macaca tonkeana) born and raised in a primate colony in France. Examination of the mass after laparotomy showed numerous vesicles identified as cysticerci of T. martis, based on the morphology of scolex and hooks, with confirmation by PCR amplification and sequence analysis of the mitochondrial cytochrome c oxidase subunit 1 (cox1) and NADH dehydrogenase subunit 1 (nad1) genes. Exeresis of the lesion was not possible and praziquantel $(5.7 \mathrm{mg} / \mathrm{kg}$ ) was given twice at an interval of 3 days. The abdominal mass was greatly diminished upon examination 2 months later and no signs of recurrence were noticed during the following 4 years.
\end{abstract}

Conclusions: This is the first report of T. martis cysticercosis in a monkey. This record and the recent first description of an ocular T. martis cysticercosis in a human show the susceptibility of primates to T. martis and its zoonotic potential. This taeniid species must be considered in the differential diagnosis of cysticercosis in primates.

Keywords: Taenia martis, Cysticercosis, Zoonosis, Macaca tonkeana, France

\section{Findings}

Non-human primates might act as aberrant hosts for a number of cestode species after peroral infection and larval development in extra-intestinal locations can have potentially severe clinical consequences [1-6]. In most cases the circumstances of infection of captive monkeys remains unclear [3]. Tonkean macaques (Macaca tonkeana, Cercopithecidae) are housed in social groups in large enclosures, and are often used for ethological research [7]. Taenia martis (Zeder, 1803) is a tapeworm that develops in the small intestine of wild carnivores (Mustelidae). In

\footnotetext{
* Correspondence: julie.brunet@unistra.fr

${ }^{1}$ Institut de Parasitologie et Pathologie Tropicale, EA 7292, Fédération de Médecine, Translationelle, Université de Strasbourg, 3 rue Koeberlé, 67000 Strasbourg, France

${ }^{2}$ Faculté de pharmacie de Strasbourg, 74 route du Rhin, 67401 IIIkirch, France Full list of author information is available at the end of the article
}

Europe it is commonly found in Martes foina, the stone marten, and in M. martes, the pine marten. Other mustelids, and more rarely canids, might also act as definitive hosts [8]. The stone marten is established in the Northern Hemisphere and is widely found in France with the highest population densities reported in eastern regions [9]. T. martis has been observed in martens in Italy, Germany and Switzerland $[10,11]$ but there is a lack of information concerning its distributional range in France. However, cestodes found in Martes foina near Nancy and Paris, which were originally described as T. intermedia (Rudolphi, 1809), were later classified as T. m. martis [12,13]. T. martis is maintained in a wild-animal cycle between carnivores and small rodents which act as intermediate hosts, mainly Myodes voles and Apodemus field mice. In Europe, prevalences of $T$. martis larvae in different rodents have been

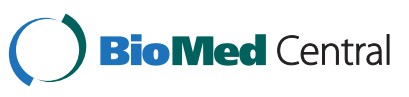

(c) 2014 Brunet et al.; licensee BioMed Central Ltd. This is an Open Access article distributed under the terms of the Creative Commons Attribution License (http://creativecommons.org/licenses/by/4.0), which permits unrestricted use, distribution, and reproduction in any medium, provided the original work is properly credited. The Creative Commons Public Domain Dedication waiver (http://creativecommons.org/publicdomain/zero/1.0/) applies to the data made available in this article, unless otherwise stated. 
reported to vary between $0.95 \%$ in bank voles (Clethrionomys [currently Myodes] glareolus) in the French Pyrenees, $2 \%$ in Apodemus flavicollis in Switzerland, and 22\% in musk rats (Ondatra zibethicus) in Belgium [11,14,15]. Recently, a first case of cysticercosis due to T. martis was observed in a human patient in Germany that shows the zoonotic potential of this cestode species [16]. The susceptibility of primates to $T$. martis infection is also supported by the present case of a peritoneal cysticercosis due to T. martis in a Tonkean macaque that, to the best of our knowledge, had never been reported before in a non-human primate.

The animal was a subadult 3-year-old male Tonkean macaque with a weight of $5.2 \mathrm{~kg}$, born and raised at the Strasbourg University Centre of Primatology, located near the Niederhausbergen forest (Alsace, northeastern France). The monkey was kept in a social group of 16 Tonkean macaques dedicated to ethological studies and housed in a semi free-range parkland closed by wire fencing. The animals feed on fruits and seeds provided by the Centre and on natural vegetation foraged in the park. Inside indoor-cages they have access to water and bananaflavoured monkey chunks ad libitum. A preventive anthelmintic treatment is administered twice a year (ivermectin $1 \mathrm{mg} / 3 \mathrm{~kg}$ subcutaneously, then fenbendazole $48 \mathrm{mg} / \mathrm{kg}$ orally, 6 months later). No abnormalities were reported for the infected animal until March 2009 when an abdominal mass $( \pm 10 \mathrm{~cm} \times 5 \mathrm{~cm})$ was detected at palpation during a routine check-up. No other clinical signs such as fever, diarrhea, anorexia or weight loss were observed. Blood tests revealed an increased alkaline phosphatase level (1610 UI/l) and a mild anaemia: haemoglobin $9.1 \mathrm{~g} / \mathrm{dl}$ (reference range: $12.2 \pm 0.8 \mathrm{~g} / \mathrm{dl})$, haematocrit $32.2 \%(40.3 \pm 3.7 \%)$, erythrocytes $5.53 \mathrm{M} / \mathrm{mm}^{3}\left(6.5 \pm 0.71 \mathrm{M} / \mathrm{mm}^{3}\right)$. Other values were within normal range. Abdominal echography was performed and the lesion was visualized in the upper left part of the abdomen, obviously between the liver and the left kidney. After celiotomy, the mass appeared embedded in the mesentery (Figure 1). It contained hundreds of ellipsoidal to spherical transparent vesicles ranging from 5 to $30 \mathrm{~mm}$ in length. The vesicles had a white, opaque area at one pole and a tapering end at the opposite, some with an elongated extremity. No budding of daughter cysts was observed. They were identified as cysticerci at microscopic examination. Each cysticercus contained a single invaginated scolex ( $1 \mathrm{~mm}$ in diameter), with 4 suckers and 28 to 30 rostellar hooks arranged in two rows (Figure 2). The hooks had the same morphological aspect (upper edge nearly straight; handle thin, longer and in the same axis than the blade; blade short, rather abruptly curved; guard very prominent) and measured 140 to $160 \mu \mathrm{m}$ and 180 to $212 \mu \mathrm{m}$ in length for small and large hooks, respectively (Figure 3).

Morphology of the cysticerci and rostellar hooks, and comparison with the closely related species $T$. crassiceps, led

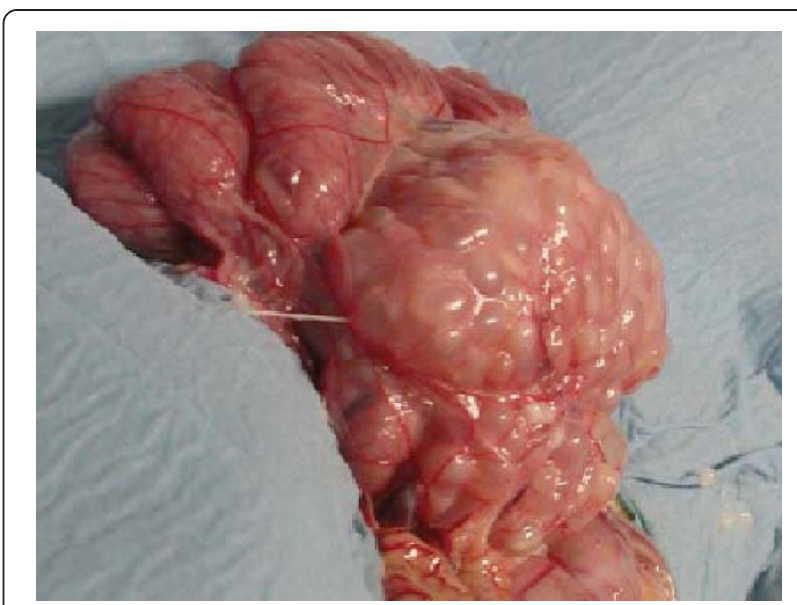

Figure 1 Aspect of the lesion after celiotomy. A vesicular mass embedded in the mesentery is shown. Some isolated cysticerci (5 to $30 \mathrm{~mm}$ long) are located at the right bottom.

to the identification of $T$. martis $[8,17,18]$. Molecular tools confirmed the morphological identification. Sequences of the mitochondrial cytochrome c oxidase subunit 1 (cox1) and NADH dehydrogenase subunit 1 (nad1) genes were amplified by PCR with primer pairs JB3/JB4.5 and JB11/ JB12 [19,20]. The sequences showed identities of $99.8 \%$ (438/439 bp, nad1, GenBank accession number EU544606) and $99.7 \%(382 / 383 \mathrm{bp}$, cox1, AB731758) with sequences published for $T$. martis. Sequence homologies with the closely related species $T$. twitchelli and $T$. crassiceps were 94.0\% (346/368 bp, EU544598) and 90.6\% (347/383 bp, AF216699) for cox1 and 86.8\% (381/439 bp, EU544650) and 82.7\% (363/439 bp, EU544600) for nad1, respectively. Phylogenetic tree was drawn by using the sequences obtained in this study as well as sequences available for representative Taenia species in GenBank (Figure 4). Diagnosis of peritoneal cysticercosis due to $T$. martis was therefore established.

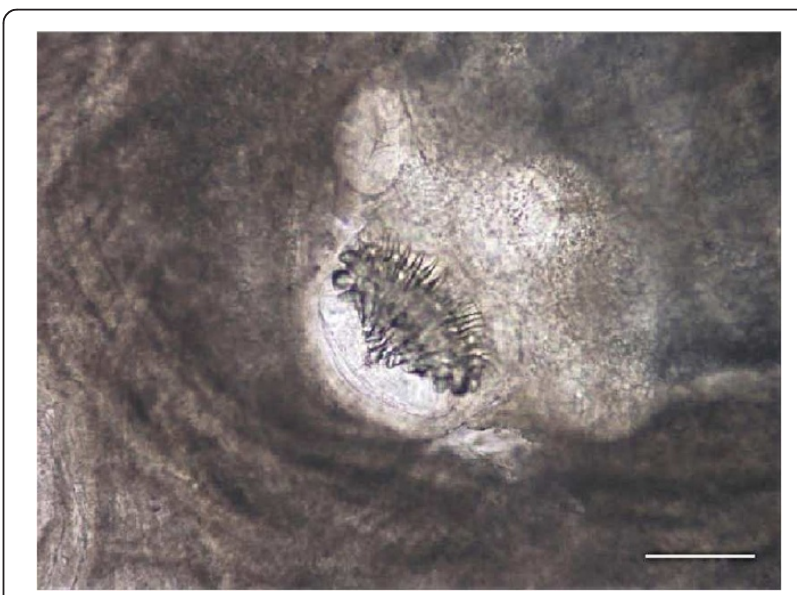

Figure 2 Close-up appearance of the invaginated scolex inside a cysticercus. Scale bar $250 \mu \mathrm{m}$. 


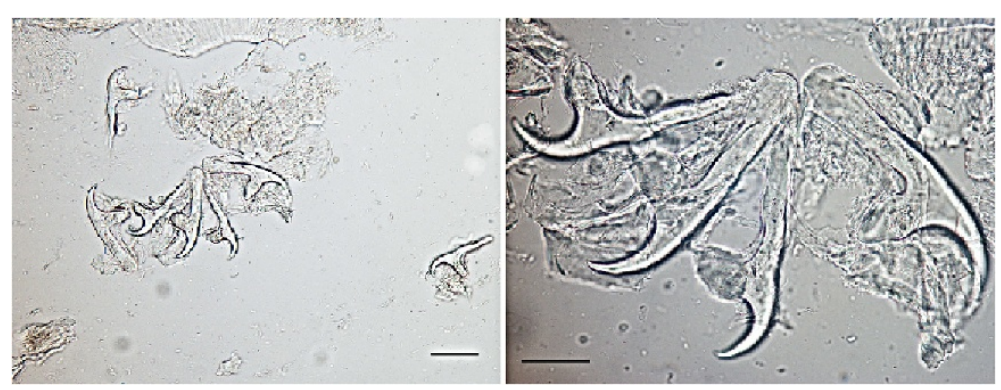

Figure 3 Morphology of small and large rostellar hooks of Taenia martis from the present case (left: scale bar $100 \mu \mathrm{m}$; right: scale bar $50 \mu \mathrm{m})$.

Surgical exeresis of the parasitic mass was not possible because of its localization and structure. Praziquantel $(5.7 \mathrm{mg} / \mathrm{kg}$, intramuscularly) was given twice at an interval of 3 days. Two months later, the abdominal mass was no longer palpable and the ultrasonography confirmed its dramatic decrease. No signs of recurrence were noticed during the 4-year follow-up period. The monkey exhibited normal growth and is presently healthy, and socializes perfectly within the group.

The case of peritoneal cysticercosis caused by $T$. martis described herein in a Tonkean macaque, constitutes a first record of a metacestodosis in this mammalian host. Diagnosis of $T$. martis cysticercosis is difficult because clinical signs are not specific. Different etiologies were suspected for the abdominal mass detected in the macaque. Abdominal tumor and other metacestodoses, including

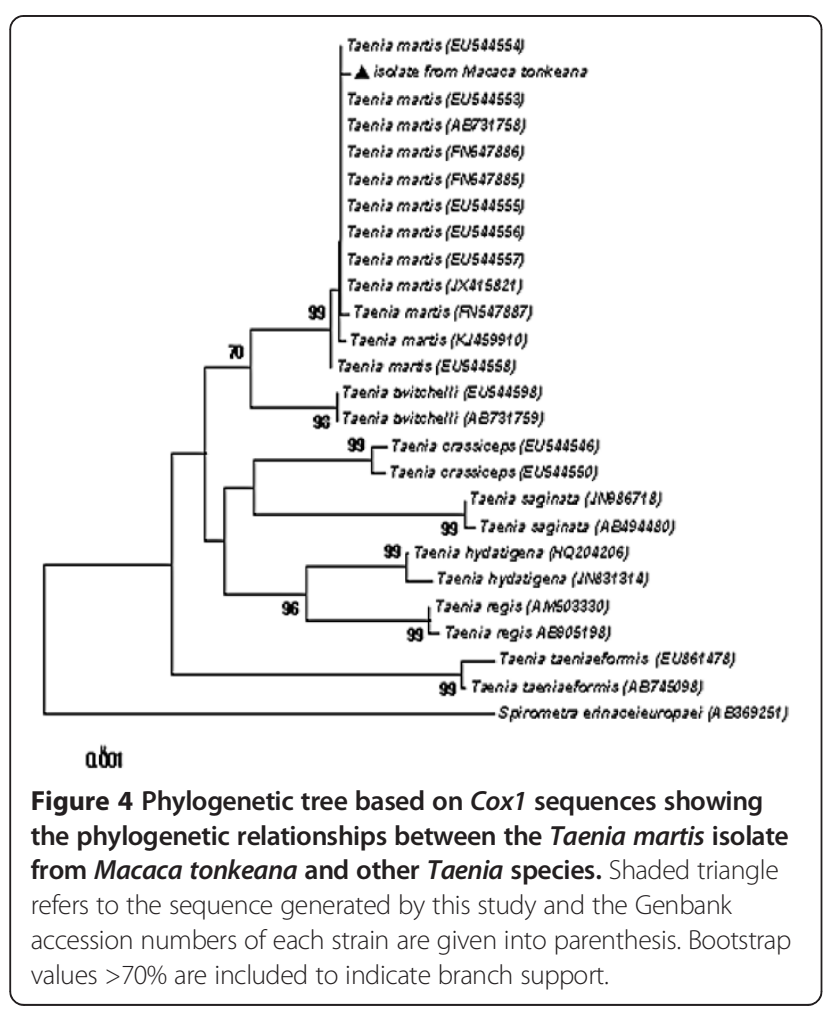

alveolar echinococcosis (AE) were initially considered. $\mathrm{AE}$ has been described in captive monkeys including other Macaca spp., and Echinococcus multilocularis is endemic in the Alsace region where the animal lives [3,6,21]. The parasites sampled from the lesion were diagnostic for cysticercosis but identification of Taenia species is challenging due to the similarities of their morphological characteristics [22]. Cysticerci of T. crassiceps, T. hydatigena and T. solium have been described in non-human primates. In the current case, some larvae showed a strobila-like structure, which is commonly seen in T. polyacantha [23]. However, the size of the small hooks and, most importantly, the total number of hooks in the present case clearly distinguished it from T. polyacantha (112-148 $\mu \mathrm{m}$ and 62 hooks). Due to the size of the cysticerci and their high number, $T$. crassiceps infection was also suspected, but comparison of scolices and hooks with those of $T$. crassiceps collected from a fox and a dog, and the absence of budding cysticerci in our case, ruled out this hypothesis (Figure 5) $[8,17,18]$.

In the present case, the completion of the cestode lifecycle is highly probable in the environment of the park as small rodents and carnivores including martens were regularly observed in the close vicinity. The infection of the monkey was likely through ingestion of taeniid eggs during foraging activities, which are quite developed in Tonkean macaques [7]. Taeniid eggs might contaminate soil and grass when scattered by rain from faeces of wild carnivores, which are often found near the fences or possibly inside the enclosure as access of martens to this wooded park is not excluded. Direct infection by picking the potentially contaminated faeces, especially when they contain fruit stones or during grooming from the fur of monkeys from the ground, are other hypotheses. In our case, clinical evolution was quite favourable. Although praziquantel had demonstrated a variable efficacy in the treatment of metacestodoses $[17,24]$, this cestodicidal drug was chosen because its injectable administration to the macaque was easier and more reliable than fenbendazole or albendazole, which would have required daily oral administration for several weeks. The localized infection observed in this macaque and the complete cure without surgical resection could be 


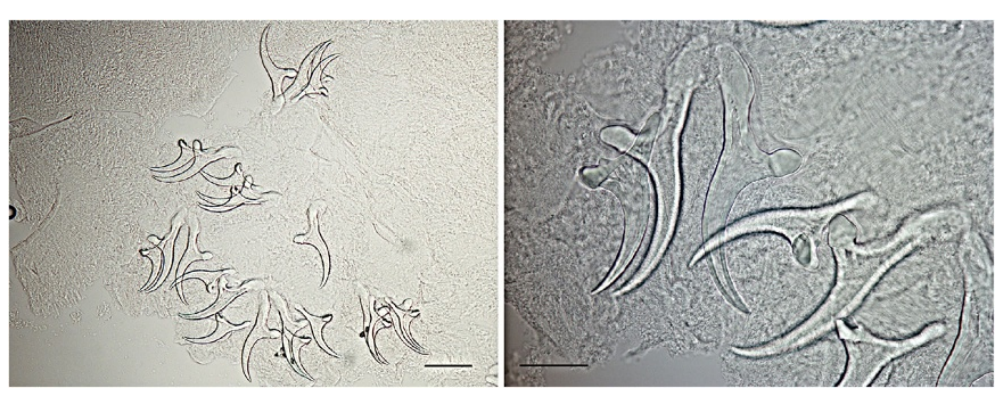

Figure 5 Morphology of small and large rostellar hooks of $T$. crassiceps from a fox (left: scale bar $100 \mu \mathrm{m}$; right: scale bar $50 \mu \mathrm{m}$ ).

explained by a high sensitivity of $T$. martis larvae to praziquantel, by adequate host defenses (as no sign of immunosuppression was observed in the animal), and also by the absence of proliferation of the parasites. Indeed, the fully-developed cysticerci of $T$. martis are non-multiplying larvae contrary to those of $T$. crassiceps which proliferate by budding $[8,17,25]$. In the case of $T$. martis metacestodosis reported recently in an immunocompetent woman in southeastern Germany, the lesion was due to a single cyst localized in the eye and the cure was obtained by surgical removal of the parasite [16]. The present report shows the susceptibility of macaque to $T$. martis larvae and indicates the occurrence of an environmental contamination with $T$. martis eggs. It highlights the potential risk of infection for captive monkeys and also for humans with this taeniid species, which should be considered in the etiology of atypical cysticercosis cases.

\section{Competing interests}

The authors declare no conflict of interests.

\section{Authors' contributions}

All authors read and approved the final version of the manuscript.

\section{Acknowledgements}

We thank Dr Bruno Polack from the Ecole Nationale Vétérinaire d'Alfort for technical assistance with some photographs. We thank Dr. Holly Tuten for editing the manuscript. We would like to thank Dr Bruno Mathieu for establishing the neighbour-joining tree.

\footnotetext{
Author details

${ }^{1}$ Institut de Parasitologie et Pathologie Tropicale, EA 7292, Fédération de Médecine, Translationelle, Université de Strasbourg, 3 rue Koeberlé, 67000 Strasbourg, France. ${ }^{2}$ Faculté de pharmacie de Strasbourg, 74 route du Rhin, 67401 Illkirch, France. '3Service de Parasitologie-Mycologie \& INRA, AFSSA, ENVA, UPVM, UMR 956 BIPAR, École Nationale Vétérinaire d'Alfort, 7, avenue du Général de Gaulle, 94704 Maisons-Alfort, Cedex, France. ${ }^{4}$ Centre de Primatologie UdS - SILABE (Simian Laboratory Europe) ADUEIS, Fort Foch, 67207 Niederhausbergen, France. ${ }^{5}$ Institute of Parasitology, Vetsuisse Faculty, University of Zurich, Winterthurerstr. 266a, CH-8057 Zurich, Switzerland. ${ }^{6}$ Clinique vétérinaire des Halles, 28 rue du faubourg Saverne, 67000 Strasbourg, France.
}

\section{References}

1. Ezzat MA, Gaafar SM: Tetrathyridium sp. in a Sykes' monkey (Cercopithecus albigularis) from Giza Zoological Gardens. Egypt J Parasitol 1951, 37:392-394.

2. Fincham JE, Seier JV, Verster A, Rose AG, Taljaard JJ, Woodroof CW, Rutherfoord GS: Pleural Mesocestoides and cardiac shock in an obese vervet monkey (Cercopithecus aethiops). Vet Pathol 1995, 32:330-333.

3. Deplazes P, Eckert J: Veterinary aspects of alveolar echinococcosis-a zoonosis of public health significance. Vet Parasitol 2001, 98:65-87.

4. Tsubota K, Nakatsuji S, Matsumoto M, Fujihira S, Yoshizawa K, Okazaki Y, Murakami Y, Anagawa A, Oku Y, Oishi Y: Abdominal cysticercosis in a cynomolgus monkey. Vet Parasitol 2009, 161:339-341.

5. Luzón M, de la Fuente-Lopez C, Martinez-Nevado E, Fernandez-Moran J, Ponce-Gordo F: Taenia crassiceps cysticercosis in a ring-tailed lemur (Lemur catta). J Zoo Wildl Med 2010, 41:327-330.

6. Rehmann P, Grone A, Gottstein B, Vollm J, Sager H, Janovsky M, Bacciarini LN: Detection of Echinococcus multilocularis infection in a colony of cynomolgus monkeys (Macaca fascicularis) using serology and ultrasonography. J Vet Diagn Invest 2005, 17:183-186.

7. Sueur C, Briard L, Petit O: Individual analyses of Lévy walk in semi-free ranging Tonkean macaques (Macaca tonkeana). PLoS One 2011, 6(10): e26788. doi:10.1371/journal.pone.0026788. Epub 2011 Oct 26.

8. Loss-Frank B: An up-date of Vester's (1969) "Taxonomic revision of the genus Taenia Linnaeus"(Cestoda) in table format. Syst Parasitol 2000, 45:155-183.

9. Stahl P, Léger F, Migot P: Répartition des petits carnivores en France. Saint-Benoist: Bibliographie et recommandations pour la poursuite du recueil des informations. Office National de la Chasse; 1997:82.

10. Ribas A, Milazzo C, Foronda P, Casanova JC: New data on helminths of stone marten, Martes foina (Carnivora, Mustelidae), in Italy. Helminthologia 2004, 41:59-61.

11. Mathy A, Hanosset R, Adant S, Losson B: The carriage of larval Echinococcus multilocularis and other cestodes by the musk rat (Ondatra zibethicus) along the Ourthe River and its tributaries (Belgium). J Wildl Dis 2009, 45:279-287.

12. Joyeux C, Baer JG: Sur quelques Cestodes de France. Archives du Muséum National d'Histoire Naturelle 1934, 11:157-171.

13. Rausch RL: Taenia pencei n. sp. from the Ringtail, Bassariscus astutus (Carnivora: Procyonidae), in Texas, U.S.A. Comp Parasitol 2003, 70:1-10.

14. Reperant LA, Hegglin D, Tanner I, Fischer C, Deplazes P: Rodents as shared indicators for zoonotic parasites of carnivores in urban environments. Parasitology 2009, 136:329-337.

15. Ribas A, Torre I, Feliu C, Arrizabalaga A, Casanova JC: Helminth communities of the bank vole Myodes glareolus (Rodentia, Arvicolinae) in two populations : Montseny Natural Park (north-eastern-Spain) and Pi Natural Reserve (French Pyrenees). Rev Ibero-latinoam Parasitol Int 2009, $1: 73-81$.

16. Eberwein P, Haeupler A, Kuepper F, Wagner D, Kern W, Muntau B, Racz P, Agostini H, Poppert S: Human infection with marten tapeworm. Emerg Infect 2013, 19:1152-1154.

17. Chermette R, Bussiéras J, Mialot M, Raynal PC: Subcutaneous Taenia crassiceps cysticercosis in a dog. J Am Vet Med Assoc 1993, 203:263-265.

18. Gubányi A: Morphometrics of taeniid tapeworms I. Multivariate analysis of distance measurements of the rostellar hooks. Parasi. Hung 1995, 28:21-41. 
19. Bowles J, Blair D, McManus DP: Genetic variants within the genus Echinococcus identified by mitochondrial DNA sequencing. Mol Biochem Parasitol 1992, 54:165-173.

20. Bowles J, McManus DP: NADH dehydrogenase 1 gene sequences compared for species and strains of the genus Echinococcus. Int $\mathrm{J}$ Parasitol 1993, 23:969-972.

21. Combes B, Comte S, Raton V, Raoul F, Boué F, Umhang G, Favier S, Dunoyer C, Woronoff N, Giraudoux P: Westward spread of Echinococcus multilocularis in foxes, France, 2005-2010. Emerg Infect Dis 2012, 18:2059-2062.

22. Hoberg EP: Taenia tapeworms: their biology, evolution and socioeconomic significance. Microbes Infect 2002, 4:859-866.

23. Rausch RL, Fay FH: Postoncospheral development and cycle of Taenia polyacantha Leuckart, 1856 (Cestoda: Taeniidae). Second part. Ann Parasitol Hum Comp 1988, 63:334-348.

24. Papini R, Matteini $A$, Bandinelli $P$, Pampurini F, Mancianti F: Effectiveness of praziquantel for treatment fo peritoneal larval cestodiasis in dogs: A case report. Vet Parasitol 2010, 170:158-161.

25. Basso W, Rutten M, Deplazes P, Grimm F: Generalized Taenia crassiceps cysticercosis in a chinchilla (Chinchilla lanigera). Vet Parasitol 2014, 199:116-120.

doi:10.1186/1756-3305-7-422

Cite this article as: Brunet et al.: First case of peritoneal cysticercosis in a non-human primate host (Macaca tonkeana) due to Taenia martis. Parasites \& Vectors 2014 7:422.

\section{Submit your next manuscript to BioMed Central and take full advantage of:}

- Convenient online submission

- Thorough peer review

- No space constraints or color figure charges

- Immediate publication on acceptance

- Inclusion in PubMed, CAS, Scopus and Google Scholar

- Research which is freely available for redistribution 